\title{
Home Food Environments of Mothers in South-Eastern Africa and California-An Illustration of Global Extremes
}

\author{
Emma Scudero ${ }^{1}$, Peggy Papathakis ${ }^{2}$, Andrew Schaffner $^{3} \&$ Suzanne Phelan ${ }^{1}$ \\ ${ }^{1}$ Department of Kinesiology \& Public Health \& Center for Health Research; California Polytechnic State \\ University, San Luis Obispo, CA, USA \\ ${ }^{2}$ Department of Food Science \& Nutrition \& Center for Health Research; California Polytechnic State University, \\ San Luis Obispo, CA, USA \\ ${ }^{3}$ Statistics Department \& Center for Health Research; California Polytechnic State University, San Luis Obispo, \\ CA, USA \\ Correspondence: Suzanne Phelan, Department of Kinesiology \& Public Health \& Center for Health Research; \\ California Polytechnic State University, San Luis Obispo, CA, USA.
}

Received: July 21, 2021 Accepted: September 28, 2021 Online Published: October 12, 2021

doi:10.5539/gjhs.v13n11p35

URL: https://doi.org/10.5539/gjhs.v13n11p35

\begin{abstract}
Introduction: The type and availability of food in the home is known to directly shape food intake and weight status, but cross-cultural differences remain poorly documented.

Objective: The purpose of this study was to describe and compare the home food environments of low-income, childbearing women living in a low-income country (Malawi) and a high-income country (United States).

Methods: A home food environment survey was available in 714 mothers in Malawi (mean BMI 19.5, mean age 22.1 years) and 371 in California (mean BMI 31.8, mean age 28.1 years).

Results: Mothers in California vs. Malawi had on average (SD) 22.8 (4.4) vs. 1.2 (1.4) different food items in the home. The women in California had an abundance of fruits and vegetables that were virtually absent in the homes of Malawian women. The most prevalent food in the homes in Californian women was rice (in 97\% homes) and in Malawian women was corn flour (in $47 \%$ of homes).

Conclusions: Given the global extremes in food availability, efforts to address over and under food availabilities in the homes of childbearing women need to move beyond country centric approaches. It is time to consider maternal and child health as a global priority.
\end{abstract}

Keywords: global health, health disparities, home environment, maternal and child health, weight status

Highlights: Childbearing women living in a low-income and a high-income countries experience extreme differences in home food availability and weight status yet face similar risks of adverse maternal and child health outcomes.

\section{Introduction}

Despite vastly different sociocultural contexts, childbearing women in both low- and high-income countries share many of the same health burdens. In low-income countries, malnutrition is related primarily to lack of nutrient variety, poverty and access to foods. Underweight mothers face elevated risks of hypertension, pre-eclampsia (Siza (2008), preterm birth and infant death (Hawkes, Haddad, \& Udomkesmalee, 2015; Katz et al., 2013). Additionally, infants are at risk of being small-for-gestational-age (SGA)(Katz et al., 2013), having low height, low birthweight, low head circumference, low developmental quotient (Bhutta, Darmstadt, Hasan, \& Haws, 2005; Katz et al., 2013; Luyckx \& Brenner, 2015) and long-term risks of obesity and diabetes. In higher income countries, although malnutrition is related primarily to excess food variety and obesity, mothers face similar increased risks of hypertension, pre-term birth, miscarriage, stillbirth, SGA, and additional risks of large for gestational age (LGA) babies and long-term risks for obesity and diabetes. In both low- and higher-income countries, these disease burdens disproportionally affect the lowest income and most disadvantaged women (Swinburn et al., 2019). The COVID-19 pandemic has exacerbated a transcontinental food emergency, with impending threats to the food environment and nutrition, which is expected to be severe in the most vulnerable populations (Huizar, Arena, \& 
Laddu, 2020).

Much attention has been paid to the global economic and multinational food system forces that shape differences in food availability, accessibly, and prevalence of underweight, obesity, and poor health outcomes in low vs. higher income countries (World Health Organization, 2018). However, few studies have described food availability in the homes of childbearing women. The type and availability of food in the home is known to directly shape food intake and weight status, (Gorin et al., 2008; Patterson, Kristal, Shannon, Hunt, \& White, 1997) but cross-cultural differences remain poorly documented. Documenting the differences in the home food environment of childbearing women from low vs. higher income countries could help shed light on the global concern that extremely different food environments may result in opposite etiologies for women (underweight and obesity), but lead to similarly devastating health outcomes for both women and children across the globe. The purpose of this study was to compare the home food environments of low-income, childbearing women living in a low-income country (Malawi) and a high-income country (United States).

\section{Methods}

This was a cross-sectional comparison study that included baseline data from two studies: The Mamachiponde (Glosz, Schaffner, Reaves, Manary, \& Papathakis, 2018) study in Malawi and the Fit Moms/Mamas Activas (Phelan et al., 2017) study in the California, USA. Both studies were approved by the California Polytechnic State University (Cal Poly) Institutional Review Board (IRB); the Mamachiponde study was also approved by IRBs at Washington University (St. Louis) and College of Medicine at University of Malawi (Blantyre). All participants in both studies provided written informed consent; verbal informed consent was also obtained from non-literate Malawian women.

The Mamachiponde study in Malawi was conducted between March 2014 and December 2015. The purpose of the study was to determine the efficacy of different food and diet supplements vs. standard care on maternal and infant birth weight and health outcomes; results have been published previously (Callaghan-Gillespie, 2017; Glosz et al., 2018). Malawi, a southeastern African nation, ranks among the poorest in the world (Group, 2019). An estimated $70.3 \%$ of people live below the International Poverty level of $\$ 1.90$ per day (Group, 2019). In Malawi among women of reproductive age $8.8 \%$ of women have a body mass index (BMI) $<18.5 \mathrm{~kg} / \mathrm{m}^{2}$ and $28.0 \%$ are anemic (Macro, 2010). The Mamachiponde study recruited moderately malnourished pregnant women $\geq 16$ years. Other eligibility criteria included fundal height of $<35 \mathrm{~cm}$ and willingness to return to antenatal clinic every 2 weeks for follow-up throughout their pregnancy and at 6 and 12 weeks postpartum.

The Fit Moms/Mamas Activas study was conducted in California, the most populous (Bureau, 2019) state in USA, which is considered a high-income country (T. W. Bank, 2016). Fit Moms/Mamas Activas tested the 12-month efficacy of an online postpartum weight loss program for low-income women (Phelan et al., 2017). Recruitment occurred between July 2011 and May 2015 and was done in collaboration with the Women, Infants, and Children (WIC) program serving low-income women. Participant eligibility was based on self-report and included age $>18$ years, being 6-12 weeks postpartum, and with a BMI $\geq 25 \mathrm{~kg} / \mathrm{m}^{2}$ or exceeding pre-pregnancy weight by at least 4.5 $\mathrm{kg}$ (Phelan et al., 2017).

\section{Assessments}

Only data from baseline assessments of Mamachiponde and Fit Moms/Mamas Activas were included in this study. In both studies, trained Research Assistants conducted the visits. In California, participants received $\$ 25$ for completing the baseline assessment visit. In Malawi, no honorarium was provided. In both studies, mothers were asked to report on their age, family income, race/ethnicity, education, marital status, and number of people living in the home. In both studies, maternal weight was assessed in lightweight clothing using a calibrated scale. Height was measured without shoes.

In California, the home food environment was measured using the Home Food Inventory Questionnaire (Fulkerson et al., 2008). This self-report questionnaire lists a series of 35 common foods in the American home, but is not an exhaustive list of all possible foods in a home. This measure has shown to have acceptable validity compared with observational measures of the home environment (Fulkerson et al., 2008) and has been used in a variety of settings and populations in the United States (Raynor, Polley, Wing, \& Jeffery, 2004; Gorin et al., 2008). In Malawi, all foods in the home were recorded during a home visit using a check-list, with additional items recorded so that $100 \%$ of all food in the home was captured. For the current study, data from the Malawi study was overlaid on the checklist used in the California study.

\section{Statistics}

Descriptive statistics, chi-square, and two-sample t-tests were used to describe and compare the sociodemographic 
and home food environmental differences between women in Malawi and in California. Pearson's product moment partial correlation coefficients were used separately in women from Malawi and women from California to examine the relationships between total foods in the home and maternal BMI, adjusting for maternal age. Results were declared statistically significant at the $\alpha=0.05$ level. The SPSS (25.0.0) statistical package was used for all analyses.

\section{Results}

Participants from the California sample were, on average 28 years old; most (79\%) had completed at least $8^{\text {th }}$ grade and had a BMI in the overweight (39\%) or obesity (57\%) classification. By contrast, Malawian participants were on average younger at 22 years old, and most ( $88 \%)$ did not complete secondary school; despite being on average 19 weeks pregnant, $100 \%$ were classified as underweight by mid-upper arm circumference $<23 \mathrm{~cm}$. Examining income, $19 \%$ of California participants reported a household income of less than $\$ 10,000 /$ year in contrast to $99 \%$ of Malawian participants (Table 1).

Table 1. Demographics of women in Malawi and California

\begin{tabular}{llll}
\hline & Malawi & California & P value \\
& $\mathbf{N}=\mathbf{7 1 4}$ & $\mathbf{N}=\mathbf{3 7 1}$ & \\
\hline Age & $22.1(5.7)$ & $28.1(5.4)$ & 0.0001 \\
\hline Highest education, junior high or less & $88.8 \%$ & $21.7 \%$ & 0.0001 \\
\hline Race/ethnicity & & & 0.0001 \\
$\quad$ Hispanic heritage, & $0 \%$ & $81.6 \%$ & \\
$\quad$ African heritage, & $100 \%$ & $1.9 \%$ & \\
\hline Income less than $\$ 10,000 /$ year & $98.9 \%$ & $18.9 \%$ & \\
\hline Married & $72.5 \%$ & $80.2 \%$ & 0.0001 \\
\hline Number people in household & 1.6 & 2.1 & \\
\hline Maternal Weight Status & & & \\
$\quad$ BMI $\left(\mathrm{kg} / \mathrm{m}^{2}\right) \dagger$ & $19.5(1.2)^{*}$ & $31.8(5.2)$ & \\
$\quad$ Underweight $\left(<18.5 \mathrm{~kg} / \mathrm{m}^{2}\right)$ & NA & $0.0 \%$ & \\
$\quad$ Normal weight $\left(18.5-24.9 \mathrm{~kg} / \mathrm{m}^{2}\right)$ & NA & $2.4 \%$ & \\
$\quad$ Overweight $\left(25-29.9 \mathrm{~kg} / \mathrm{m}^{2}\right)$ & NA & $39.1 \%$ & \\
$\quad$ Obese $\left(>=30 \mathrm{~kg} / \mathrm{m}^{2}\right)$ & NA & $57.4 \%$ & \\
\hline
\end{tabular}

Values listed are mean (SD) or N (\%).

*Note that Malawian women were pregnant and on average 19 weeks gestation.

$\dagger$ categorization of weight status of pregnant women using BMI is not possible

Women in California vs. Malawi had significantly more food types overall in their homes (Table 2). On average, women in California had 22.8 (SD 4.3) types of foods in the home vs. only 1.2 (SD 1.4) types of foods in the homes of women in Malawi. For every food listed, a significantly greater proportion of women in California than Malawi reported currently having the food in their home (Table 2). The most prevalent food in the homes of Californian women was rice, found in the homes of $97 \%$ of women in California compared with only $7 \%$ of homes of women in Malawi. In Malawi, the most prevalent food was cereal (corn flour/meal), found in the homes of $47 \%$ of women in Malawi compared with $63 \%$ of the homes of women in California. Beans were another prevalent food in the homes of both Malawian and Californian women ( $26 \%$ vs. $97 \%$ of homes, respectively). The women in California had an abundance of fruits and vegetables that were virtually absent in the homes of Malawian women, such as cantaloupe, mango and papaya (54.2\% vs $17.2 \%$ ). Only $18 \%$ of homes of women in Malawi had tomatoes (compared to $87.9 \%$ in California), none of the Malawian homes had carrots or mixed vegetables, lettuce, apples, applesauce or pears. Compared to California homes, Malawian homes also had lower quantities of meat protein $(81.9 \%$ vs $0.3 \%$ ) and non -meat protein $(97.6 \%$ vs $25.6 \%)$. While $20.8 \%$ to $83.3 \%$ of California homes had sugar-sweetened foods, such as fruit juice, cookies, frozen desserts, pastries, and cakes and pies, these were 
completely absent in Malawian homes.

Table 2. Home Food Inventory from participant households in California (CA) and Malawi*

\begin{tabular}{|c|c|c|c|c|}
\hline & Food & $\begin{array}{l}\text { Malawi } \\
(n=714)\end{array}$ & $\begin{array}{l}\text { CA } \\
(n=371)\end{array}$ & p- Value \\
\hline 1. & Cooked cereals (including oatmeal, Cream of Wheat, grits, blue corn mush) & $47.1 \%$ & $62.8 \%$ & 0.000 \\
\hline 2. & $\begin{array}{l}\text { Beans such as pinto, black beans, black-eyed peas, butter beans, red beans, } \\
\text { garbanzos, baked beans, adzuki beans }\end{array}$ & $25.6 \%$ & $97.6 \%$ & 0.000 \\
\hline 3. & Tomatoes (including pico de gallo), tomato juice & $17.5 \%$ & $87.9 \%$ & 0.0001 \\
\hline 4. & Cantaloupe, mango, papaya & $17.2 \%$ & $54.2 \%$ & 0.000 \\
\hline 5. & Rice (including White, Brown or Wild) & $7.0 \%$ & $97.0 \%$ & 0.000 \\
\hline 6. & Oranges, grapefruit, tangerines & $1.0 \%$ & $74.9 \%$ & 0.000 \\
\hline 7. & Beef, pork, lamb & $0.3 \%$ & $81.9 \%$ & 0.000 \\
\hline 8. & Carrots or mixed vegetables containing carrots & $0.0 \%$ & $92.7 \%$ & 0.000 \\
\hline 9. & Lettuce & $0.0 \%$ & $89.5 \%$ & 0.000 \\
\hline 10. & Apples, applesauce, pears & $0.0 \%$ & $88.1 \%$ & 0.000 \\
\hline 11. & Cheese & $0.0 \%$ & $84.6 \%$ & 0.000 \\
\hline 12. & Other fruit juices, fortified drinks & $0.0 \%$ & $83.3 \%$ & 0.000 \\
\hline 13. & Other cold cereals that are low in sugar such as Corn Flakes, Rice Krispies, Kix & $0.0 \%$ & $81.7 \%$ & 0.000 \\
\hline 14. & Nuts or Peanut Butter & $0.0 \%$ & $81.4 \%$ & 0.000 \\
\hline 15 . & Mayonnaise & $0.0 \%$ & $81.4 \%$ & 0.000 \\
\hline 16. & High fiber, bran or granola cereals, shredded wheat & $0.0 \%$ & $79.5 \%$ & 0.000 \\
\hline 17. & Dark break (including whole wheat, rye, pumpernickel, other high fiber bread) & $0.0 \%$ & $77.4 \%$ & 0.000 \\
\hline 18. & Butter or Margarine & $0.0 \%$ & $74.9 \%$ & 0.000 \\
\hline 19. & $\begin{array}{l}\text { White bread (including hamburger or hot dog buns, bagels, baguettes, pita bread, } \\
\text { English muffins, French Bread, yeast bread, taro bread, sandwich bread) }\end{array}$ & $0.0 \%$ & $73.9 \%$ & 0.000 \\
\hline 20. & Broccoli & $0.0 \%$ & $68.7 \%$ & 0.000 \\
\hline 21. & Potato chips, corn chips, or tortilla chips & $0.0 \%$ & $67.9 \%$ & 0.000 \\
\hline 22. & Hot dogs, bologna, lunch meat & $0.00 \%$ & $67.9 \%$ & 0.000 \\
\hline 23. & Orange juice or grapefruit juice & $0.00 \%$ & $67.1 \%$ & 0.000 \\
\hline 24. & Bacon, sausage and other breakfast meet & $0.00 \%$ & $65.0 \%$ & 0.000 \\
\hline 25. & Cookies & $0.00 \%$ & $62.8 \%$ & 0.000 \\
\hline 26. & Frozen desserts such as ice cream & $0.00 \%$ & $56.1 \%$ & 0.000 \\
\hline 27. & Spinach & $0.00 \%$ & $40.20 \%$ & 0.000 \\
\hline 28. & Cream and whipped cream & $0.00 \%$ & $38.50 \%$ & 0.000 \\
\hline 29. & Milk & $0.00 \%$ & $36.10 \%$ & 0.000 \\
\hline 30. & Pastries such as doughnuts or sweet rolls & $0.00 \%$ & $36.10 \%$ & 0.000 \\
\hline 31. & Mustard greens, turnip greens, collard greens, kale & $0.00 \%$ & $28.80 \%$ & 0.000 \\
\hline 32. & Sweet potatoes, yams & $0.00 \%$ & $27.20 \%$ & 0.000 \\
\hline 33. & Highly fortified cereals such as product 19 , Total or Most & $0.00 \%$ & $25.30 \%$ & 0.000 \\
\hline 34. & Cakes and pies & $0.00 \%$ & $20.80 \%$ & 0.000 \\
\hline
\end{tabular}

* Note that the Home Food Inventory Questionnaire was validated in the United States; some of the foods listed might not be available in Malawi. 
Although the most prevalent foods (corn flour and beans) in the homes of Malawian women were captured in the survey, 25 foods in the homes of some Malawian women such as corn and okra (Table 3) were not captured on the California survey; similarly, an unknown number of foods in the American homes were not captured by the survey.

Table 3. Percentage of Malawian women $(\mathrm{N}=714)$ with foods that were observed in their home but not captured on the American Home Food Inventory

\begin{tabular}{|c|c|c|}
\hline 1. & Corn & $28.2 \%$ \\
\hline 2. & Okra & $9.7 \%$ \\
\hline 3. & Vegetable Oil & $9.2 \%$ \\
\hline 4. & Sugar & $8.4 \%$ \\
\hline 5. & Chicken eggs & $7.4 \%$ \\
\hline 6. & Onion (anyezi) & $7.3 \%$ \\
\hline 7. & Green Maize & $6.6 \%$ \\
\hline 8. & Cucumber (Nkhaka) & $3.6 \%$ \\
\hline 9. & Matemba (type of fish) & $3.4 \%$ \\
\hline 10. & Mulamba (type of fish) & $2.7 \%$ \\
\hline 11. & Cassava (chinangwa) & $2.5 \%$ \\
\hline 12. & Sugarcane & $2.5 \%$ \\
\hline 13. & Masawa & $2.0 \%$ \\
\hline 14. & Animal Fat & $2.0 \%$ \\
\hline 15. & Makakana (type of fish) & $1.5 \%$ \\
\hline 16. & Green beans (zitheba) & $1.5 \%$ \\
\hline 17. & Squash (Maungu) & $1.4 \%$ \\
\hline 18. & Eggplant (Mambiringano) & $1.3 \%$ \\
\hline 19. & Avocado & $1.1 \%$ \\
\hline 20. & Irish Potato & $0.6 \%$ \\
\hline 21. & Lilly Bulbs & $0.4 \%$ \\
\hline 22. & Chambo (type of fish) & $0.4 \%$ \\
\hline 23. & Guinea Fowl eggs & $0.4 \%$ \\
\hline 24. & Crabs (Nkhanu) & $0.1 \%$ \\
\hline 25. & Ants (Ngumbi) & $0.1 \%$ \\
\hline
\end{tabular}

After adjusting for age, the total number of food types in the home was inversely related to maternal BMI in participants residing in California $(r=-0.12 ; p=0.02)$ but was not significantly related to the BMI of women in Malawi $(\mathrm{r}=-0.02, \mathrm{p}=0.63)$. 


\section{Discussion}

The purpose of this study was to illustrate differences in the home food environments of childbearing women at increased risk of poor birth-related outcomes living in the low-income country of Malawi and the high-income state of California in the United States. Pregnant mothers in Malawi were underweight and on average had only 1-2 types of foods in the home, despite a higher variety of food types being prevalent in Malawian marketplaces. By contrast, mothers in California had overweight and obesity and more than 22.8 different types of foods in the home including many energy-dense and sugar-sweetened food options.

Observational studies have shown that in low-and middle-income countries, such as Malawi, limited food availability and underweight is commonplace (Ezzati, 2004) while in higher income countries such as the United States excess food variety and overweight and obesity are most prevalent (Monteiro, Moura, Conde, \& Popkin, 2004). These extremes in weight and home food environmental conditions are linked with many of the same negative health outcomes, including increased risks of maternal pre-eclampsia, miscarriages, and infants who are born with SGA, cognitive impairments, and a higher risk of lifelong disease. Wildly different home environments, as well as sociopolitical, economic, and cultural settings can yield different maternal weight status, but similarly negative health burdens for low-income mothers and their children.

Surprisingly, in California a greater number of types of foods in the home was related with lower BMI among California postpartum women in the current study. Participants in California were part of the WIC program that provides food assistance to support the purchase of healthy foods, including fruits and vegetables. Greater availability and variety in these foods in the home could serve to lower BMI. Research in economically disadvantaged homes in the United States has shown that a higher number of types of nutrient dense foods, such as fruits and vegetables, lower risk of obesity and related diseases (Nour, Lutze, Grech, \& Allman-Farinelli, 2018). In Malawi, the number of foods in the home was not statistically related with maternal BMI during pregnancy. This could reflect a restricted range of foods in the home of Malawian women overall or other unmeasured factors that shaped BMI during pregnancy and food availability in their country. While the present study illustrates vast differences in quantity and type of foods available across homes of two extremely different environments, linkages with weight status and health outcomes is an important avenue for future research.

Relatedly, comparison of these two vastly different sociopolitical and cultural environments should not overshadow the extremes of malnutrition existing within both California and Malawi. An increasingly prevalent "double burden" of co-occurring underweight and obesity has been documented in both countries (Development, 2018). Food insecurity occurs in resource-poor and -rich countries, underlying many of health problems that plague the world today (Tzioumis \& Adair, 2014; Abdullah, 2015; Development, 2018). Moreover, in both Malawi and the United States, people with low-income are the most likely to experience the extremes of underweight and obesity, and being unable to afford nutritious foods on a consistent basis (Darmon, Briend, \& Drewnowski, 2004; Drewnowski \& Specter, 2004; Wrigley, Warm, \& Margetts, 2003; Walker, Keane, \& Burke, 2010). In Malawi, for example, apples, applesauce and pears are imported, increasing costs and limiting availability. Although more economic fruit options are available locally in Malawi, the cost of imported produce is a barrier to a diverse diet and, as a result, proper nutrition.

Despite being on opposite extremes, the underlying drivers of over and under nutrition are similar. The home environment is considered an important microenvironmental determinant of malnutrition, providing social and physical cues for both excess or inadequate calorie intake and micronutrient status (Gorin et al., 2008; Patterson et al., 1997; Strauss \& Knight, 1999). Meso and macro-level systems (e.g., schools, hospitals, transportation systems, land use, urban design) are other important determinants of food availability, weight status, and related health outcomes in both countries (Monteiro, Moura et al., 2004; Monteiro, Conde, Lu, \& Popkin, 2004). The United States has an efficient food transportation and distribution system, food production and processing technology, and governmental policies (e.g., subsidized livestock and corn) that make unhealthy foods affordable and abundant and causal agents of obesity and disease (Franck, Grandi, \& Eisenberg, 2013; Service, 2019; Siegel et al., 2016). By contrast, Malawi has less efficient food systems and the majority of food supply has been through subsistence farming (Diao, 2012; Malawi, 2017; Aragie, Pauw, \& Pernechele, 2018). As a result, poor crop yields due to variable and adverse weather events such as flooding and droughts (W. Bank, 2009; Pauw, 2011) significantly harm household economic welfare and food security (Chirwa \& Quinion, 2005) and also disproportionately affect women (Akampumuza, 2017; Denton, 2002).

Given the global extremes in food availability, which are partially illustrated in the current study, efforts to address 
over and under food availabilities need to move beyond country centric approaches. Global leaders and country ministries must coordinate strategies to reduce both nutritional deficiencies and tackle the growing global burden of obesity and related co-morbidities. Public health programs and policies must align to address both ends of the food availability spectrum and develop and test effectiveness of interventions at all system levels. Evidence-based nutrition supplement programs and weight loss interventions must be integrated into clinical settings for widespread implementation. Other papers have eloquently addressed potential multi-level solutions (Hawkes, Ruel, Salm, Sinclair, \& Branca, 2020). Table 4 provides some examples of potential global solutions consistent with other recommendations (Swinburn et al., 2019).

Table 4. Multi-level solutions to address global problem of under and excess food availability in childbearing women

Microlevel (e.g., home environment, communities)

- $\quad$ Promote diversity in food production and consumption for women living in remote areas with little access to markets.

- Include regular health check-ups for women and early detection of under- and overweight.

Mesolevel (e.g., schools, hospitals)

- Promote international exchanges to develop global strategies for addressing double burden of malnutrition among childbearing women

- Institute evidence-based, nutrition counseling programs to promote healthy eating during childbearing years.

- Ensure that nutrition guidelines for schools meet energy and nutrient needs and restrict foods, snacks, and beverages high in energy, sugar, fat, and salt.

- Promote continued education of girls in school.

Macrolevel (e.g., food, transport)

- Improve the nutritional quality of the food supply through incentives to promote community food production, permaculture, use of native foods, fortification, biofortification, and reformulation.

\section{Governance (e.g., norms, economics, policies)}

- Refocus agriculture towards the production of nutritious foods such as fruits, vegetables, nuts, legumes, and wholegrains, and making these foods more affordable for all.

- Combat climate change

For a comprehensive list of multi-level strategies, see Swinburn and colleagues. (Swinburn et al., 2019)

The current study is a short illustration of extremes in food availability in the homes of childbearing women in two different parts of the world. The current study did not examine relationships between food availability and actual food intake and adverse maternal/child health outcomes. Also, the measure of the home food environment was not comprehensive. Home Food Inventory Questionnaire was developed in the United States and assessed only a subset of array of possible foods in the home. In Malawi, a comprehensive home food assessment was conducted. While the most prevalent foods (corn flour and beans) in the homes of Malawian women were captured in the survey, some foods in the homes of Malawian women $(n=25$; Table 3$)$ and American women were not captured on the survey. While all participants were women of childbearing age, the Malawian women were pregnant and the California women were postpartum and their weight statuses differed by parent study design, preventing examination of home environments of women with normal weight. Comparing home food environments of California and Malawian women provides an opportunity to discuss global disparities in maternal home 
environments. Future research is needed to identify and address the diverse drivers that contribute to this disparity (i.e. food scarcity, inadequate nutrition education, high cost of food) and methods to address these and other determinants of home food environmental extremes in different parts of the world.

In conclusion, millions of childbearing women in the world experience malnutrition, from undernutrition to over-nutrition. Excess availability of low-nutrient dense food in the United States and inadequate availability of food in Malawi illustrate a concerning global imbalance that is affecting the health of women of reproductive age and likely the health of the subsequent generations in both countries. There are multi-level causes of malnutrition, and individuals with low income are the most affected. It is time to consider maternal and child health as global priority, warranting global governance strategies to mediate these disparities.

\section{Acknowledgments}

The Fit Moms/Mamas Activas study was funded by a National Institute of Diabetes and Digestive and Kidney Diseases grant (number: DK087889); Ms. Scudero's work on this project was supported by the Bill \& Linda Frost Fellowship at Cal Poly, San Luis Obispo. The Mamachiponde study received funding from the following sources: The Office of Global Health, Infectious Diseases, and Nutrition Bureau for Global Health, United States Agency for International Development (USAID) under terms of Cooperative Agreement No. AID-OAA-A-12- 00005, through the Food and Nutrition Technical Assistance III Project (FANTA), managed by FHI 360; Feed the Future (Peanut and Mycotoxin Innovation Lab); Cal Poly, San Luis Obispo; California Agricultural Research Initiative, San Luis Obispo; U.S. Dairy Export Council; Dairy Research Initiative; Sackler Institute; and, the Hickey Family Foundation.

Scudero conceived of the study, analyzed the data, and drafted the manuscript. Phelan implemented the Fit Moms/Mamas Activas study and contributed to data analysis, data interpretation, and study write-up. Papathakis implemented the Mamachiponde study and contributed to data interpretation, and write-up. Dr. Andrew Schaffner contributed to data analysis, data interpretation, and write-up.

\section{Competing Interests Statement}

Phelan reports a grant from WW, unrelated to this work. The authors report no other conflicts.

\section{References}

Abdullah, A. (2015). The Double Burden of Undernutrition and Overnutrition in Developing Countries: an Update. Curr Obes Rep, 4(3), 337-349. https://doi.org/10.1007/s13679-015-0170-y

Akampumuza, P., \& Matsuda, H. (2017). Weather shocks and urban livelihood strategies: The gender dimension of household vulnerability in the Kumi District of Uganda. Journal of Development Studies, 53(6), 953-970. https://doi.org/10.1080/00220388.2016.1214723

Aragie, E., Pauw, K., \& Pernechele, V. (2018). Achieving food security and industrial development in Malawi: Are export restrictions the solution? World Dev, 108, 1-15. https://doi.org/10.1016/j.worlddev.2018.03.020

Bank, T. W. (2016). Data: High income. Retrieved from https://data.worldbank.org/income-level/high-income

Bank, W. (2009). Malawi: Economic Vulnerability and Disaster Risk Assessment. Retrieved from https://data.worldbank.org/income-level/high-income

Bhutta, Z. A., Darmstadt, G. L., Hasan, B. S., \& Haws, R. A. (2005). Community-based interventions for improving perinatal and neonatal health outcomes in developing countries: a review of the evidence. Pediatrics, 115(2 Suppl), 519-617. https://doi.org/10.1542/peds.2004-1441

Bureau, U. S. C. (2019). State Populations Totals and Components of Change: 2010-2019. Retrieved from https://www.census.gov/data/tables/time-series/demo/popest/2010s-state-total.html\#par_textimage_157443 9295

Callaghan-Gillespie, M., Schaffner, A. A., Garcia, P., Fry, J., Eckert, R., Malek, S., ... \& Papathakis, P. C. (2017). Trial of ready to use supplemental food and corn soy blend in pregnant Malawian women with moderate malnutrition: a randomized, controlled clinical trial. Am J Clin Nutr. https://doi.org/10.3945/ajcn.117.157198

Chirwa, P., \& Quinion, A. (2005). Impact of soil fertility replenishment agroforestry technology adoption on the livelihoods and food security of smallholder farmers in central and southern. Malawi: InTech Rijeka, Croatia. 
Darmon, N., Briend, A., \& Drewnowski, A. (2004). Energy-dense diets are associated with lower diet costs: a community study of French adults. Public Health Nutrition, 7(1), 21-27. https://doi.org/10.1079/PHN2003512

Denton, F. (2002). Climate change vulnerability, impacts, and adaptation: Why does gender matter? Gender \& Development, 10(2), 10-20. https://doi.org/10.1080/13552070215903

Development, U. S. A. I. (2018). Malawi: Nutrition Profile. Retrieved from https://www.usaid.gov/sites/default/files/documents/1864/Malawi-Nutrition-Profile-Mar2018-508.pdf

Diao, X., Thurlow, J., Benin, S., \& Fan, S. (2012). Strategies and priorities for African agriculture: Economywide perspectives from country studies. International Food Policy Research Institute.

Drewnowski, A., \& Specter, S. E. (2004). Poverty and obesity: the role of energy density and energy costs. Am J Clin Nutr, 79(1), 6-16. https://doi.org/10.1093/ajen/79.1.6

Ezzati, M., Lopez, A. D., Rodgers, A. A., \& Murray, C. J. (2004). Comparative quantification of health risks: global and regional burden of disease attributable to selected major risk factors. Retrieved from https://apps.who.int/iris/handle/10665/42770

Franck, C., Grandi, S. M., \& Eisenberg, M. J. (2013). Agricultural subsidies and the American obesity epidemic. Am J Prev Med, 45(3), 327-333. https://doi.org/10.1016/j.amepre.2013.04.010

Fulkerson, J. A., Nelson, M. C., Lytle, L., Moe, S., Heitzler, C., \& Pasch, K. E. (2008). The validation of a home food inventory. Int J Behav Nutr Phys Act, 5, 55. https://doi.org/10.1186/1479-5868-5-55

Glosz, C. M., Schaffner, A. A., Reaves, S. K., Manary, M. J., \& Papathakis, P. C. (2018). Effect of Nutritional Interventions on Micronutrient Status in Pregnant Malawian Women with Moderate Malnutrition: A Randomized, Controlled Trial. Nutrients, 10(7). https://doi.org/10.3390/nu10070879

Gorin, A. A., Wing, R. R., Fava, J. L., Jakicic, J. M., Jeffery, R., West, D. S., . . and the Look, A. H. E. R. G. (2008). Weight loss treatment influences untreated spouses and the home environment: evidence of a ripple effect. International Journal of Obesity, 32(11), 1678-1684. https://doi.org/10.1038/ijo.2008.150

Group, W. B. (2019). Macro Poverty Outlook for Subsaharan Africa, Spring Meetings 2019. Retrieved from http://pubdocs.worldbank.org/en/720441492455091991/mpo-ssa.pdf

Hawkes, C., Haddad, L., \& Udomkesmalee, E. (2015). The Global Nutrition Report 2015: what we need to do to advance progress in addressing malnutrition in all its forms. Public Health Nutrition, 18(17), 3067-3069. https://doi.org/10.1017/S1368980015003158

Hawkes, C., Ruel, M. T., Salm, L., Sinclair, B., \& Branca, F. (2020). Double-duty actions: seizing programme and policy opportunities to address malnutrition in all its forms. Lancet, 395(10218), 142-155. https://doi.org/10.1016/S0140-6736(19)32506-1

Huizar, M. I., Arena, R., \& Laddu, D. R. (2020). The global food syndemic: The impact of food insecurity, Malnutrition and obesity on the healthspan amid the COVID-19 pandemic. Prog Cardiovasc Dis. https://doi.org/10.1016/j.pcad.2020.07.002

Katz, J., Lee, A. C., Kozuki, N., Lawn, J. E., Cousens, S., Blencowe, H., . . Black, R. E. (2013). Mortality risk in preterm and small-for-gestational-age infants in low-income and middle-income countries: a pooled country analysis. Lancet, 382(9890), 417-425. https://doi.org/10.1016/S0140-6736(13)60993-9

Luyckx, V. A., \& Brenner, B. M. (2015). Birth weight, malnutrition and kidney-associated outcomes--a global concern. Nat Rev Nephrol, 11(3), 135-149. https://doi.org/10.1038/nrneph.2014.251

Macro, N. S. O. N. a. I. (2010). Malawi Demographic and Health Survey 2010. NSO and ICF Macro 2011.

Malawi, G. o. (2017). The Malawi Growth and Development Strategy (MGDS III). Retrieved from https://cepa.rmportal.net/Library/government-publications/the-malawi-growth-and-development-strategy-m gds-iii

Monteiro, C. A., Conde, W. L., Lu, B., \& Popkin, B. M. (2004). Obesity and inequities in health in the developing 
world. Int J Obes Relat Metab Disord, 28(9), 1181-1186. https://doi.org/10.1038/sj.ijo.0802716

Monteiro, C. A., Moura, E. C., Conde, W. L., \& Popkin, B. M. (2004). Socioeconomic status and obesity in adult populations of developing countries: a review. Bull World Health Organ, 82(12), 940-946.

Nour, M., Lutze, S. A., Grech, A., \& Allman-Farinelli, M. (2018). The Relationship between Vegetable Intake and Weight Outcomes: A Systematic Review of Cohort Studies. Nutrients, 10(11). https://doi.org/10.3390/nu10111626

Patterson, R. E., Kristal, A. R., Shannon, J., Hunt, J. R., \& White, E. (1997). Using a brief household food inventory as an environmental indicator of individual dietary practices. Am J Public Health, 87(2), 272-275. https://doi.org/10.2105/AJPH.87.2.272

Pauw, K., Thurlow, J., Bachu, M., \& Van Seventer, D. E. (2011). The economic costs of extreme weather events: a hydrometeorological CGE analysis for Malawi. Environment and Development Economics, 16(2), 177-198. https://doi.org/10.1017/S1355770X10000471

Phelan, S., Hagobian, T., Brannen, A., Hatley, K. E., Schaffner, A., Munoz-Christian, K., \& Tate, D. F. (2017). Effect of an Internet-Based Program on Weight Loss for Low-Income Postpartum Women: A Randomized Clinical Trial. JAMA, 317(23), 2381-2391. https://doi.org/10.1001/jama.2017.7119

Raynor, H. A., Polley, B. A., Wing, R. R., \& Jeffery, R. W. (2004). Is dietary fat intake related to liking or household availability of high- and low-fat foods? Obes Res, 12(5), 816-823. https://doi.org/10.1038/oby.2004.98

Service, U. S. D. $\quad$ o. A. E. R. (2019). Policy. Retrieved from https://www.ers.usda.gov/topics/animal-products/dairy/policy.aspx

Siegel, K. R., McKeever Bullard, K., Imperatore, G., Kahn, H. S., Stein, A. D., Ali, M. K., \& Narayan, K. M. (2016). Association of Higher Consumption of Foods Derived From Subsidized Commodities With Adverse Cardiometabolic Risk Among US Adults. JAMA Intern Med, 176(8), 1124-1132. https://doi.org/10.1001/jamainternmed.2016.2410

Siza, J. E. (2008). Risk factors associated with low birth weight of neonates among pregnant women attending a referral hospital in northern Tanzania. Tanzan $J$ Health Res, 10(1), 1-8. https://doi.org/10.4314/thrb.v10i1.14334

Strauss, R. S., \& Knight, J. (1999). Influence of the home environment on the development of obesity in children. Pediatrics, 103(6), e85. https://doi.org/10.1542/peds.103.6.e85

Swinburn, B. A., Kraak, V. I., Allender, S., Atkins, V. J., Baker, P. I., Bogard, J. R., . . Dietz, W. H. (2019). The Global Syndemic of Obesity, Undernutrition, and Climate Change: The Lancet Commission report. Lancet, 393(10173), 791-846. https://doi.org/10.1016/S0140-6736(18)32822-8

Tzioumis, E., \& Adair, L. S. (2014). Childhood dual burden of under- and overnutrition in low- and middle-income countries: a critical review. Food Nutr Bull, 35(2), 230-243. https://doi.org/10.1177/156482651403500210

Walker, R. E., Keane, C. R., \& Burke, J. G. (2010). Disparities and access to healthy food in the United States: A review of food deserts literature. Health Place, 16(5), 876-884. https://doi.org/10.1016/j.healthplace.2010.04.013

World Health Organization, F. a. A. O. o. t. U. N. (2018). Driving commitment for nutrition within the UN Decade of Action on Nutrition: policy brief.

Wrigley, N., Warm, D., \& Margetts, B. (2003). Deprivation, Diet, and Food-Retail Access: Findings from the Leeds 'Food Deserts' Study. Environment and Planning A: Economy and Space, 35(1), 151-188. https://doi.org/10.1068/a35150 


\section{Copyrights}

Copyright for this article is retained by the author(s), with first publication rights granted to the journal.

This is an open-access article distributed under the terms and conditions of the Creative Commons Attribution license (http://creativecommons.org/licenses/by/4.0/). 